\title{
The roles of the outdoors and occupants in contributing to a potential pan-microbiome of the built environment: a review
}

Marcus H. Y. Leung and Patrick K. H. Lee*

\begin{abstract}
Recent high-throughput sequencing technology has led to an expansion of knowledge regarding the microbial communities (microbiome) across various built environments (BEs). The microbiome of the BE is dependent upon building factors and conditions that govern how outdoor microbes enter and persist in the BE. Additionally, occupants are crucial in shaping the microbiome of the BE by releasing human-associated microorganisms and resuspending microbes on floors and surfaces. Therefore, both the outdoors and occupants act as major sources of microorganisms found in the BE. However, most characterizations of the microbiome of the BE have been conducted in the Western world. Notably, outdoor locations and population groups present geographical variations in outdoor and human microbiomes, respectively. Given the influences of the outdoor and human microbiomes on BE microbiology, and the geographical variations in outdoor and human microbiomes, it is likely that the microbiomes of BEs also vary by location. The summation of microbiomes between BEs contribute to a potential BE pan-microbiome, which will both consist of microbes that are ubiquitous in indoor environments around the world, and microbes that appear to be endemic to particular geographical locations. Importantly, the BE pan-microbiome can potentially question the global application of our current views on indoor microbiology. In this review, we first provide an assessment on the roles of building and occupant properties on shaping the microbiome of the BE. This is then followed by a description of geographical variations in the microbiomes of the outdoors and humans, the two main sources of microbes in BEs. We present evidence of differences in microbiomes of BEs around the world, demonstrating the existence of a global pan-microbiome of the BE that is larger than the microbiome of any single indoor environment. Finally, we discuss the significance of understanding the BE pan-microbiome and identifying universal and location-specific relationships between building and occupant characteristics and indoor microbiology. This review highlights the much needed efforts towards determining the pan-microbiome of the $\mathrm{BE}$, thereby identifying general and location-specific links between the microbial communities of the outdoors, human, and BE ecosystems, ultimately improving the health, comfort, and productivity of occupants around the world.
\end{abstract}

Keywords: Indoor built environments, Geography, Building designs, Outdoor air, Human microbiome, Pan-microbiome

\footnotetext{
* Correspondence: patrick.kh.lee@cityu.edu.hk

School of Energy and Environment, City University of Hong Kong, Tat Chee

Avenue, Kowloon B5423-AC1, Hong Kong
} 


\section{Background}

Recent advances in culture-independent, DNA sequencing (hereafter referred to as high-throughput sequencing, HTS) technology have led to unprecedented insights into the diverse repertoire of microorganisms (microbiome), including bacteria, fungi, viruses, and parasites, that are present in various environments. It is now appreciated that cultivation-based methods represent $<0.001 \%$ of the total microbial life truly present [1]. HTS has been used to characterize microbial communities at much greater depth and in different environments, highlighting the importance of microbial life in driving biological and biochemical processes in various ecosystems [2-5].

Of these different ecosystems, the microbiome of the indoor environment (or built environment, BE) has been investigated in detail over the past decade. Recent efforts to characterize microbial community of the $\mathrm{BE}$ are motivated by the fact that modern urbanites allocate approximately $90 \%$ of their times indoors [6], making the BE a predominant habitat for humans in the developed world. In the developing world, trends towards urbanization and modernization will likely be concomitant with people spending more time indoors. Currently, over $70 \%$ of the fastest growing urban centers are situated in developing countries [7]. In addition, approximately $70 \%$ of the world's population will live in urban areas by the year 2050 [8]. From a microbial exposure perspective, the majority of microorganisms encountered by most humans' lifetime will therefore be those present in the $\mathrm{BE}$, such as those in indoor air [9-11] and on various surfaces [12-14]. Interests in characterizing the microbiome of the $\mathrm{BE}$ are based on the importance of understanding associations between occupant health and microbial exposure in indoor settings. While exposure to specific allergens and pathogens within the BE can result in adverse health outcomes [15-17], studies have shown that the nature of microbial communities as a whole within the BE also affects health of occupants. For instance, exposure to greater repertoire of microorganisms, which for example can be mediated through pet ownership, may confer protection against the onset of respiratory conditions $[18,19]$, and reduced microbial diversities in indoor settings have been linked to the development of respiratory conditions including asthma [20, 21]. In addition, microbiome characterizations in public indoor spaces can provide valuable information regarding public health surveillance and the transmission of infectious agents [22-30]. Also, in a recent review, Hoisington et al. [31] propose that understanding the relationships between the microbiomes of the $\mathrm{BE}$ and its occupants can help improve the occupants' mental well-being, as numerous bacterial and fungal species detected indoors have been documented to affect psychological health.
Given the increasing trend towards an indoor lifestyle, and the significance of the $\mathrm{BE}$ microbiome on human health, a greater understanding of the factors that shape microbial communities in the $\mathrm{BE}$ is imperative in improving occupant health and productivity [32]. Currently, microbiome studies involving HTS have been applied to a diverse array of indoor environments, including but not limited to residences [9, 12, 14, 21, 33-41], schools [11, 17, 42, 43], hospitals [22-25, 29, 30], public transports [26-28], aircrafts [44], shopping malls [45], fitness centers [46, 47], offices $[43,48,49]$, and child-care facilities [50]. These studies demonstrate that HTS technology is a feasible and comprehensive tool to ultimately understand the $\mathrm{BE}$ microbiome with which the occupants interact. Importantly, these studies have demonstrated that the $\mathrm{BE}$ presents microbial communities distinct from other ecosystems and presents a unique assemblage $([22,51,52]$ and reviewed in [53]). Our recent knowledge regarding the microbial community of the $\mathrm{BE}$ is no longer limited to the types of microorganisms present, but also how various building and occupant characteristics alter the $\mathrm{BE}$ microbiome, and potentially occupant health. Therefore, rationales for characterizing microbial assemblages in the BE have become multifaceted and interdisciplinary in nature, combining elements of engineering, architecture, and microbiology. Also, regardless of the building types and locations in question, the outdoors and occupants have shown to be among the principal sources of microorganisms detected in BEs [9, 11-14, 36, 54]. Thus, various building and occupant characteristics and activities shape the microbial assemblage of the BE around the world, by influencing how outdoor- and human-associated microbes (unless otherwise indicated, microbes refer to bacteria and fungi in this review) are introduced into the indoors.

Despite the knowledge we have acquired regarding the roles of building and occupant characteristics on structuring the microbiome of the $\mathrm{BE}$, the majority of these studies pertain to the Western world (Table 1 and Additional file 1). Conversely, studies characterizing the microbiomes of BEs in other geographical regions, where the majority of the world's population are based, are limited (Table 1). Microbiome differences in local, regional, and continental scales have been documented across ecosystems [17, 55, 56]. Given that geographical clustering of microbial communities has been documented in the outdoors and humans (the two major sources of microorganisms in BEs, among others, recently reviewed in [57]), it is envisioned that such variations will create differences in microbiomes of BEs globally, because of the fundamental roles of the outdoors and occupants have on the $\mathrm{BE}$ microbiome. Ultimately, this collection of microbiomes contributes to a global BE panmicrobiome, which comprises of microorganisms that are detected in BEs across continental scales, as well as 
Table 1 Countries, and their populations, where HTS-based microbiome works of the BE have been conducted. A total of 72 studies involving HTS are included based on search terms "indoor microbiome," "built environment microbiome," "built environment microbiota," and "indoor microbial community" on the NCBI database and Google Scholar (reference list available as Additional file 1). All studies were funded by the corresponding countries where the samples were collected. According to the reference list compiled, over $90 \%$ of the world's population live in countries where microbiome data for the BE is unavailable

\begin{tabular}{|c|c|c|c|c|}
\hline Sampling location & Region & Study count ${ }^{a}$ & Population (million) ${ }^{b}$ & Reference \\
\hline Austria & Europe & 3 & 8.5 & {$[1-3]$} \\
\hline Canada & North America & 2 & 35.5 & {$[4,5]$} \\
\hline Finland & Europe & 2 & 5.5 & {$[6,7]$} \\
\hline France & Europe & 2 & 66.2 & {$[8,9]$} \\
\hline Germany & Europe & 1 & 80.9 & [10] \\
\hline Hong Kong & Asia & 2 & 7.2 & {$[11,12]$} \\
\hline International $^{c}$ & - & 5 & - & {$[13-17]$} \\
\hline Singapore & Asia & 1 & 5.5 & [18] \\
\hline South Korea & Asia & 2 & 50.4 & {$[19,20]$} \\
\hline Spain & Europe & 1 & 46.4 & {$[21]$} \\
\hline Taiwan $^{\text {b }}$ & Asia & 1 & 23.4 & [22] \\
\hline United States & North America & 50 & 318.9 & {$[23-72]$} \\
\hline Others & - & 0 & $6,612.0$ & \\
\hline
\end{tabular}

aist of references available as Additional file 1

${ }^{b}$ Except for Taiwan, figures based on 2014 data from The World Bank (http://data.worldbank.org/indicator/SP.POP.TOTL). Taiwan figures based on 2014 data from IndexMundi (http://www.indexmundi.com/taiwan/demographics_profile.html)

'Studies involving comparison of the microbiome of the BE in multiple locations and countries. All four international studies were funded by the USA

endemic microbes present in specific geographical locations. Understanding the pan-microbiome, which is greater than the microbiome of any single $\mathrm{BE}$, has significant importance. For example, microbiome analyses of the BEs around the world may potentially uncover novel indoor microbial members that are specific to particular geographical locations. As the majority of the population lives outside of the Western hemisphere, it is uncertain whether our current insight on microbial community of the BE can be applied across areas with different living conditions, properties, and outdoor and occupant source microbiomes [58, 59]. In order to devise globally representative and location-specific strategies for improving indoor qualities within BEs, the differences in the microbiomes of the outdoors and occupants, acting as sources of microorganisms detected in the $\mathrm{BE}$, and how that influence the pan-microbiome of the $\mathrm{BE}$, need to be considered and appreciated.

The key purposes of this review are to discuss the three fundamental and universal factors (mode of ventilation, building design, and occupancy) that shape the microbiome of the $\mathrm{BE}$ irrespective of geography, followed by a review of the evidence showing geography-based differences in the microbiomes of the outdoors, occupants, and the $\mathrm{BE}$. We conclude the review with a description of the challenges and future directions in BE microbiome research, paying attention to the need to identify both universal and location-specific relationships between building and occupant characteristics and the microbiome of the indoor environment. Through this review, we encourage a greater focus on the characterization of microbiomes in indoor environments in geographically distinct locations, leading to the discovery of a BE pan-microbiome, which will ultimately assist in improving occupant health and comfort in BEs around the world.

\section{Microbiome of the BE before the era of HTS}

Although HTS-based studies have drastically empowered scientists in understanding the shaping factors of the microbiome of the $\mathrm{BE}$, interests in determining the microbial repertoire of the $\mathrm{BE}$ arose before the advent of HTS. These pre-HTS studies pave way for dedicated efforts in determining the relationships between environmental and anthropogenic factors and properties that help shape the microbiome of the BE.

Through earlier culture-dependent studies [60-64], Gram-positive bacteria, including human-associated Staphylococcus, Micrococcus, and soil dweller Bacillus, and fungi including Penicillium, Aspergillus, and Cladosporium, are among the most commonly cultured microorganisms from the $\mathrm{BE}$. The roles of the outdoor environment and occupants in shaping the microbiome of the BE are evident, when Pasanen et al. [61] demonstrated that BEs in farmlands differ in their microbiomes compared to urban BEs, potentially mediated by occupants introducing microorganisms associated with rural terrains. Additionally, the community of cultivable microbes may differ depending on the building type and 
design [64]. Therefore, these studies already demonstrate the importance of building design, the outdoors and occupants in shaping the microbiome of the BE. Culture-based studies also highlight the importance of determining the microbiome of the $\mathrm{BE}$ in terms of occupant and public health, as potentially pathogenic microorganisms can be cultured in various indoor environments $[65,66]$.

However, our insight into the microbial diversity of the $\mathrm{BE}$ at that time was limited to microbes that are cultivable under specific, stringent, and artificial laboratory conditions. Indeed, in studies that employ both culture and clone library-based sequencing, the bacterial and fungal diversities of the $\mathrm{BE}$ detected through sequencing greatly surpasses that of culture methods, impacting researchers to reconsider their views on the true breadth of microbial life of the indoors $[15,62,67,68]$. Specifically, the enhanced diversity information obtained from clone library sequencing enables more in-depth analyses of how the outdoor environment and occupant activities shape the indoor microbiome $[62,69,70]$, as well as how potential pathogens detected within indoor spaces may pose health risks for its occupants $[15,71]$. Of interest, Täubel and colleagues [69] demonstrate that the inclusion of multiple household samples increases the total number of taxa detected, indicating that the idea of a $\mathrm{BE}$ pan-microbiome was appreciated even prior to when HTS became commonplace in indoor microbiome studies.

\section{Fundamental factors affecting BE microbiomes Mode of ventilation and building design}

HTS studies analyzing the effect of ventilation modes of various $B E s[10,11,22,52]$ show that, in addition to the distinction of microbial communities in the $\mathrm{BE}$ compared to that of the outdoors, mechanically ventilated rooms also present different microbiomes to that of naturally ventilated indoor spaces. Naturally ventilated rooms tend to contain more similar microbiomes from adjacent outdoor air compared to that of mechanically ventilated rooms $[11,22]$. Rooms with natural ventilation are perhaps more likely to facilitate microbes from the outdoors to enter $[10,11,27]$. Consistent with this, the abundances of microbes with outdoor origins have been shown to be greater in dust samples from naturally ventilated rooms [43]. At the same time, depending on the building type, mechanical ventilation can include filters, preventing some of the outdoor microbes and particulates from traveling into the $\mathrm{BE}[11,22]$. In addition to facilitating or impeding outdoor microbes from entering BEs, ventilation is likely to affect additional environmental parameters, including indoor temperature, humidity, airflow rates, and carbon dioxide levels. These parameters have also been reported to affect indoor microbial community compositions and may select for the survival of specific microbial taxa [22, 26, 33, 43]. Therefore, the type of ventilation mode selected for a particular $\mathrm{BE}$ is a major player in shaping the microbial community composition of the BE, by directly affecting how outdoor microbes enter into BE spaces, at the same time modulating environmental and selective properties within the $\mathrm{BE}$.

In addition to ventilation strategy, building designs, such as room type, floor area, floor level, and spatial relationships with neighboring indoor spaces, can affect the microbiology of the indoor environment. Building design and architectural elements possibly shape the microbiome of the $\mathrm{BE}$ by mediating how air and microbes within the air are circulated within the BE. In offices and classrooms, Kembel and colleagues [43] report microbiome variations between rooms that differ in their accessibilities to adjacent indoor spaces (hallways with connections to a large number of other rooms have distinct microbiome to that of restrooms and rooms with fewer connections). Similarly, Adams et al. [52] document the variations in microbial communities between different room types. Specifically, outdoor-associated bacteria decrease in abundances within the indoor environment as one moves away from the outdoors into more interior parts of the BE. Moreover, different rooms within buildings may present distinct microbial communities and differ in microbial diversity [9, 12, 24, 43, 52]. For example, restrooms may present distinct microbiomes compared to living rooms and kitchens in residential settings $[9,12,52]$, whereas microbiomes between rooms within other types of BEs may also vary $[24,43]$. This is perhaps partly explained by variations in architectural strategies and floor plan adopted between space types to maximize occupant efficiency and functionality (for example, hallways with connection to other indoor spaces compared to restrooms with low connectivity to other indoor rooms [43]).

Indoor environments such as metropolitan subway systems provide a useful model for exploring the relationship between $\mathrm{BE}$ and outdoor microbiomes, and how this is shaped by architectural and usage variation. For example, subways around the world differ in a number of properties, including ventilation at stations and trains, platform location (indoor or outdoor, aboveground or underground), and presence of floor-toceiling safety screen doors between platforms and trains. These properties together can govern how air is introduced and circulated inside the subway environment [72]. Robertson et al. [27] characterized the air microbiome of the New York City metro network, showing efficient air mixing and hence insignificant variation in community compositions between subway and outdoor air. This is likely due to the piston effect of carriages in 
the absence of mechanical ventilation. In contrast, in the Hong Kong (HK) subway network [26], where mechanical ventilation is adopted and safety screen doors are installed where possible, a higher bioaerosol microbial diversity in outdoor air compared to that of the subway suggests that complete air mixing does not take place. Furthermore, according to their architectural relationship to the outdoors, different aboveground or underground subway lines show variations in microbial assemblages, and that the adjacent outdoor air is likely to be a major microbiome source for each subway line. Taken together, the works described above demonstrate the interplay between ventilation mode, architectural choices, and microbial community of the $\mathrm{BE}$, governing how air from the outside is introduced into and circulated in the indoors. Further works in the BE microbiome research community can be focused on the temporal aspects of building or room-associated microbiome variations, so as to determine whether the observed differences in the microbial communities between BEs are temporally stable [73]. However, building design and room types also impinge on the density and activity of occupants, which, as we describe below, act as another major force configuring the microbiome within the $\mathrm{BE}$.

\section{Human microbiome and occupancy}

Given that humans shed approximately $10^{7}$ bacteria per person per hour in indoor settings [74], and that humans spend most of their times indoors, it should come as no surprise that human presence and activities contribute to the $\mathrm{BE}$ microbiomes. Indeed, to varying extents, microbiome studies of the $\mathrm{BE}$ all indicate the influence of occupants on shaping indoor microbial assemblages. Studies using source tracking and taxonomic approaches generally agree that microbiomes from indoor air and surfaces contain microorganisms predominantly associated with the human skin, with the human gut, oral, and urogenital microbiomes acting as additional sources of microbial communities in the $\mathrm{BE}[12,26,28,36,39,42$, 47, 52, 75]. Microbiome characterizations conducted in residences demonstrate that host- and householdspecific microbial communities can be detected, and at times these household microbiomes resemble that of the occupants $[9,10,12,36,52]$. Similarly, a recent chamber study reveals that occupants tend to rapidly generate a "microbial cloud," resulting in a change in the microbiome of the adjacent air compared to a vacant but otherwise identical space [76]. Interestingly, this microbial cloud is unique to each occupant at a community and a species or strain level. Similar to indoor bioaerosols, the rapid filling of a personal microbiome by its occupants also occurs along indoor floors and surfaces, demonstrating that occupants can quickly leave their microbiome fingerprint onto different ecosystems within the $\mathrm{BE}[36,47,77,78]$. Such observations have even led to the recent prospects of analyzing the microbiomes of humans and its surrounding environments for personal identification and forensic purposes [77, 79, 80].

Human contact with indoor surfaces is a way in which microbiome of the occupant affects the microbiome of indoor surfaces $[36,47,80]$. In addition to desquamation, skin-associated microbes can be transferred onto indoor surfaces and floors following physical contact. Studies investigating BE surfaces indicate both the frequency [14], as well as the nature of human contact (e.g. whether surface contact mediated with skin on handles and grips, or mediated with shoes on floor and carpets, or release of gut-associated microbes in washrooms) $[13,42,43,46,47,75]$, are associated with variations in microbiomes of different indoor areas and even on different surfaces within a single BE or room. Therefore, different sub-microbiomes may exist within an indoor space, depending on the types of contacts it has with the human body. Furthermore, longitudinal analysis reveals more extensive community dynamics on surfaces frequented by human contact, suggesting that surfaces in public areas (e.g. fitness centers, airplanes, public transports, etc.), where they are likely to come into contact with more people, may also experience greater temporal variations in their microbial communities [47] compared to a private $\mathrm{BE}$ (residential unit). These observations in general underscore how occupant contact affects microbiomes of indoor surfaces in various ways, and that understanding the types of activities that occupants engage in will aid in predicting the resulting microbial communities in different BEs.

In addition to direct contact, a number of works have shown that human occupancy and movements also affect indoor microbiomes. Re-suspension of settled dust particles via movement of the occupants has been demonstrated to be a source of indoor microbial particle emissions [17, 48, 54, 81]. Kembel et al. [43] show that indoor spaces with a high human occupancy and traffic (such as hallways) present distinct microbial communities compared to spaces with a lower human occupancy and traffic. A number of other works demonstrate that occupancy is associated with increased particle mass, microbial loads, concentration, and diversity and abundance of human-associated microbes in indoor air $[11,41,54,73,81]$. In addition, human and domesticated animal movements and activities inside and outside of the $\mathrm{BE}$ can also affect the indoor microbiome, by introducing exogenous microbial members into the $\mathrm{BE}[48,51,82,83]$. Therefore, the roles of human on shaping the microbiome of the $\mathrm{BE}$ are not limited to the human microbiome but also by occupant activities, movements, and their relationships with the immediate environments. 


\section{Geographical differences in the sources of major BE microbiomes}

\section{Geographical differences in the outdoor microbiomes}

Given the importance of the outdoor environment as a microbial source for the microbial assemblage of the $\mathrm{BE}$, changes that affect outdoor microbial community will potentially influence the microbiome of the nearby BE. The outdoor microbiome itself is a conglomerate of microorganisms from nearby soil, plant, and aquatic environments, which are renowned for their extensive microbial diversities [2, 3, 84]. Moreover, microbial compositions of these source environments are subjected to wide fluctuations of environmental conditions, facilitating the survival and growth of different microorganisms [85]. As a result, variations in the adjacent terrain will lead to different outdoor air community structures depending on location [86-88]. Consistent with this, differences in microbiomes of the atmosphere have been associated with variations in land use types. Bowers et al. [55] compare the microbiomes of the air above agricultural, suburban, and forest areas, revealing strong terrain-based clustering of microbiomes in the nearsurface atmosphere, driven by changes in the abundances of bacterial taxa indigenous of local surroundings.

In addition to geography and landform, local weather condition is another factor in structuring the microbial community of the outdoor air. Meteorological and climatic conditions affect the microbiome by governing how microbes are aerosolized, transported, and dispersed (reviewed in [89]). Specifically, weather condition potentially dictates how different sources of microbiomes contribute to the microbial community of the outdoors. For example, dryer and warmer conditions may encourage dispersal of soil- and plant-associated microbes following desiccation, while colder weather conditions may be associated with presence of coldtolerant and ice-associated microorganisms in the air [90, 91]. Also, seasonal differences may be associated with the import of air masses from different terrains, contributing to variations in microbial communities of the outdoors. Woo and colleagues [92] demonstrate that in $\mathrm{HK}$, air masses in the summer originate from the aquatic south, while air masses come from the terrestrial north during the winter. Interestingly, this seasonal air mass source difference is associated with changes in the abundances of marine and soil-associated microorganisms in the outdoor air.

Urbanization may have a negligible role in shaping outdoor microbial communities, as shown in the aforementioned HK study [92], but a separate US study demonstrates the effect of urbanization on dampening the variations in the microbiomes of different areas, such that the microbiome dissimilarities between cities are less than that of samples across rural areas [93]. Intriguingly, with a large enough sample size and the appropriate statistical predictive tools, the geographical location of a sample can be identified within a $200-\mathrm{km}$ radius based on its microbial community [94]. Taken together, these studies corroborate the endemic nature of the microbiome of the outdoors and highlight the importance of nearby landforms, as well as environmental and meteorological conditions, in understanding outdoor bioaerosol compositions across geography. Importantly, information about variations in microbiomes between locations can be applied to design predictive and computational tools useful for microbial ecologists. Such tools will ultimately help identify patterns of microbial community changes associated with geography, terrain and developments, and climatic conditions.

\section{Differences in human microbiomes based on geographical location}

The majority of the human microbiome studies to date pertain to Western subjects. Yet, global citizens are of different geographical origins, and our current knowledge about the human microbiome, and its relationships with physiologies, health, and diseases, may not reflect on population groups with discrepant lifestyles and environmental exposures. Until the last 5 years, population group differences on the human microbiome appear to have been overlooked [95]. However, recent analyses of microbial communities of population groups demonstrate that the global human microbiome community exists as a human pan-microbiome, larger than that of any single person or population group, and that lifestyle changes associated with modernization over time has led to a change in microbial communities compared to our ancestors [59, 96, 97].

Given that human occupancy and activities are major shaping forces of the microbiome of the $\mathrm{BE}$, and the human microbiome is a main source for the microbiome of indoor spaces, geography-based variations in human microbial communities will also likely contribute to a panmicrobiome of a global BE. Therefore, an appreciation for the human pan-microbiome is essential in understanding the pan-microbiome of the BE. The following section highlights the key research works dedicated to the comparison of the human microbiomes (mainly the gut, oral, and skin microbiomes, as these are the key sources of humans' influence in the microbiome of the $\mathrm{BE})$ between different population groups. We stress that microbiome differences between populations do not necessarily equate variations in microbial communities between different ethnic or racial groups. It is unlikely that ethnicity and race inherently drive microbiome differences. Hence, these broad terms should not be considered predictor variables in understanding the 
relationships between microbiomes of the occupants and that of the BE $[96,98]$. Instead, the terms ethnicity and race should be treated as starting points to uncover environmental exposures and lifestyle choices, potentially associated with ethnicity and race, that may play more direct roles in shaping the microbiomes of the occupants.

\section{Gut microbiome (GM)}

GM can spatially and temporally affect the microbial communities of indoor areas including washrooms, where usually relatively higher proportions of gutassociated microorganisms can be found [13, 43, 75]. In a study comparing GMs between cohorts, De Filippo et al. [99] attribute dietary differences as a main factor for the observed discrepancies in GMs between children in rural Burkina Faso and those in urban Italy. Their study also shows greater microbial richness and diversity in the guts of rural subjects, an observation recapitulated in later studies [58, 59, 100-102]. Researchers hypothesize that the populations of different geographical groups will adopt different dietary habits that vary in vegetable, fiber, starch and simple sugars, dairy products, and salt intakes. Subsequently, these variations will select for distinctive microbial populations and their specialized metabolic needs [103-106]. The greater diversity seen in rural cohorts around the world is also consistent with the hypothesis that westernization, industrialization, and urbanization lead to a reduction in the diversity of the GM. The loss of microbial diversity has direct health consequences, as urbanites may be more susceptible to diseases due to the loss of potentially beneficial microbes present in ancestral and tribal communities [58, 99, 102, 107]. Alternatively, in addition to the comparisons of different population groups, David et al. [108] reveal the changes in GMs of one individual, who relocated from an urban Western setting to a developing nation and subsequently adopted new dietary habits. That change in lifestyle and environmental exposure coincides with a change in GM to a different state that is reversed upon return to the subject's place of origin, providing additional evidence that lifestyle changes associated with geography can affect microbial assemblages of the gut.

\section{Oral microbiome (OM)}

Interests in deciphering inter-cohort OM differences originally stem from variations in the prevalence of oral diseases between populations [109]. A study including subjects from 12 towns globally shows that population groups by location have significant differences in the abundances of specific genera within their saliva [110]. One subsequent study, sampling multiple sites within the oral cavities (supragingival, subgingival, and saliva) of different individuals in the US, shows population- unique species (differences in community memberships between populations) and differences between populations in the abundance of shared microbial members (differences in community composition between populations) [111]. While the majority of studies are limited to characterization of bacterial communities, Ghannoum et al. [112] examined fungal communities within oral rinses from White, African-American, Asian, and Native American individuals within Cleveland, Ohio, showing population-based as well as gender-based factors in shaping the fungal communities. Despite the observations documented by these studies, they suffer from either a lack of information regarding dietary habits and other lifestyle characteristics [110-112] or from a small number of study subjects [110, 112]. Furthermore, one study [110] employs Sanger sequencing now considered to be low throughput; hence, the true population-based variations in $\mathrm{OM}$ may be underestimated. In general, population group-focused analyses on $\mathrm{OM}$ variations are limited, and more in-depth investigations on the potential roles of different population groups in shaping $\mathrm{OM}$ changes will be necessary in the future. In addition, while studies indicate the oral microbiome as a potential source of microbial community of the BE [12, 48, 54], works pertaining to the transfer of microbes from the oral cavity to indoor spaces, similar to that demonstrated for skin microbes [36], will enhance our understanding on how the OM contributes to the microbial assemblage of the BE.

\section{Skin microbiome (SM)}

The skin is the largest human organ, and its microbiome generally has the most direct relationship with the immediate environment including the $\mathrm{BE}$ (described above). Daily activities and the external surroundings will have a prominent role in shaping a subject's SM, as their activities, lifestyles, and the environments they are exposed to can potentially be inferred by the microbial populations present on various skin sites [97, 113, 114]. Skin physiologies have been shown to both differ by population group and affect the SM $([115,116]$ and reviewed in [117]). In addition to host physiological properties, anthropogenic characteristics, such as gender, age, handedness, personal hygiene, and lifestyles, have all been shown to affect SM [96, 113, 118-120]. Our comparison of SMs between urban and rural populations reveals the expansion of a global cutaneous panmicrobiome [96]. Also, we detected a relatively high abundance of Enhydrobacter in Hong Kong individuals consistent with previous studies conducted in China $[113,121]$. This genus is previously known to adopt an aquatic habitat and was only recently detected in individuals and BEs [47, 96, 121-123]. Hence, the detection of Enhydrobacter in Chinese individuals signifies that 
some microbes, previously known to be of environmental origins, may in fact be common colonizers of the human host in another part of the world.

A multi-site (including skin) analysis conducted by the Human Microbiome Project, using metagenomic analysis, examined the metabolic potential of microbial communities between individuals and population groups [4]. They show differences in the abundances of Pseudomonadales in the population groups analyzed. There was, however, no mention of population-based differences in functional potential as inferred by metagenomic analysis. Future works employing metagenomic sequencing on skin samples between populations will further enhance our understanding of how population and environmental parameters affect both the microbial populations and their metabolic potentials.

\section{Multiple BEs make up the BE pan-microbiome}

The effects of terrain, landforms, and climate, coupled with human physiological and anthropogenic properties, contribute to differences in the microbial compositions of the outdoors and occupants, two of the most important BE microbiome sources, around the world (Fig. 1). As the outdoors and occupants act as two predominant channels for introducing and emitting microorganisms into the indoors, it is anticipated that BEs around the world present distinctions in their microbial assemblages. Indeed, a number of studies have reported geographical variability in the microbial assemblage of the $\mathrm{BE}[10,17,49,51,56]$. As we discuss below, we have only begun to dissect the extensive differences in the microbiome of the BE across geography, most of which are focused on the Western world.

Assessments of fungal communities in BEs across continents demonstrate that geography, rather than building design, best explains differences in microbial communities of the indoors, with human occupancy being another strong factor in shaping fungal communities of the indoors depending on occupant density $[17,56]$. The influence of geography on fungal communities reinforces the role of outdoor environments in shaping the microbial community of the BE. Amend et al. [56] postulate that a combination of environmental selection and dispersal limitation governs the observed biogeography patterns in the $\mathrm{BE}$, and that the relative strengths of the two factors differ depending on the taxa [56, 124]. Also, in the studies of Adams et al. $[10,52]$ investigating air microbiomes in residences within a housing complex, a positive correlation between similarities in microbial communities and geographical distances is detected, providing support that dispersal limitation within the $\mathrm{BE}$ also occurs on a local scale. On the other hand, bacterial communities in the $\mathrm{BE}$ are more likely to be associated with occupant characteristics and lifestyles [51].
Nonetheless, the role of geography can potentially alter bacterial communities in the $\mathrm{BE}$ through differences in human microbiomes, which in turn determine the microbes that are emitted into the indoor space. For example, the genus Enhydrobacter, which appears to be more abundant on the skin of Chinese individuals [96, 121], is also among the most abundant genera in air and on surfaces of various BEs throughout HK $[9,26]$. Also, variations in indoor conditions that are associated with geography, such as occupant density and area size, may affect how microbes of different sources of the human microbiome (gut, mouth, skin) are released into the BE. For instance, Wilkins et al. [9] demonstrates little effect of occupants' personal microbiomes in shaping microbial communities of the residential air, which contrasts from the American study of Meadow et al. [76], but consistent with other American studies $[11,48]$ that characterize different BEs. In the HK study [9], the gut and oral microbiomes may play greater roles as sources to the microbial communities of the residences. Also, given the high abundance of skinassociated bacteria in the outdoor air in HK (perhaps more so than in the USA $[48,81]$ ) [26], the microorganisms detected in the residential air ecosystem in HK may originate from the outdoors.

Despite the current limited knowledge regarding geographical differences in indoor microbiology, the works described above have begun to allow us to appreciate that the microbiomes of different BEs consolidate to form a pan-microbiome pool that is larger than the microbiome of any single indoor environment. Also, one can deduce the nature of this pan-microbiome pool (Fig. 2). A BE pan-microbiome first contains a collection of core microorganisms that are prevalent in BEs across all or most geographical locales. Given the roles of outdoors and humans in general on the microbial communities of the $\mathrm{BE}$, core taxa within different BEs will include those commonly detected across the outdoors and the humans $[43,47,75,125]$. The size of the core microbiome, here regarded as the number of taxa included, may depend on the locations [47], the numbers [56], and the types $[9,125]$ of BEs considered. Core bacteria common to different BEs may include those frequently detected on humans (for example, Micrococcus, Acinetobacter, and Corynebacterium) but may also include members of environmental origins (phylotypes of Rhizobiales, Sphingobacteriales, and Sphingomonadales) $[9,43,125]$. In addition to the core microbiome, the majority of the diversity seen across a pan-microbiome will potentially belong to taxa that are detected in subsets of the BEs considered. These unique (or distributed) taxa may represent a large proportion of OTUs within a panmicrobiome but may not necessarily represent a large proportion of total sequences $[43,125]$. Such members can be identified through multi-study comparison of $\mathrm{BE}$ 


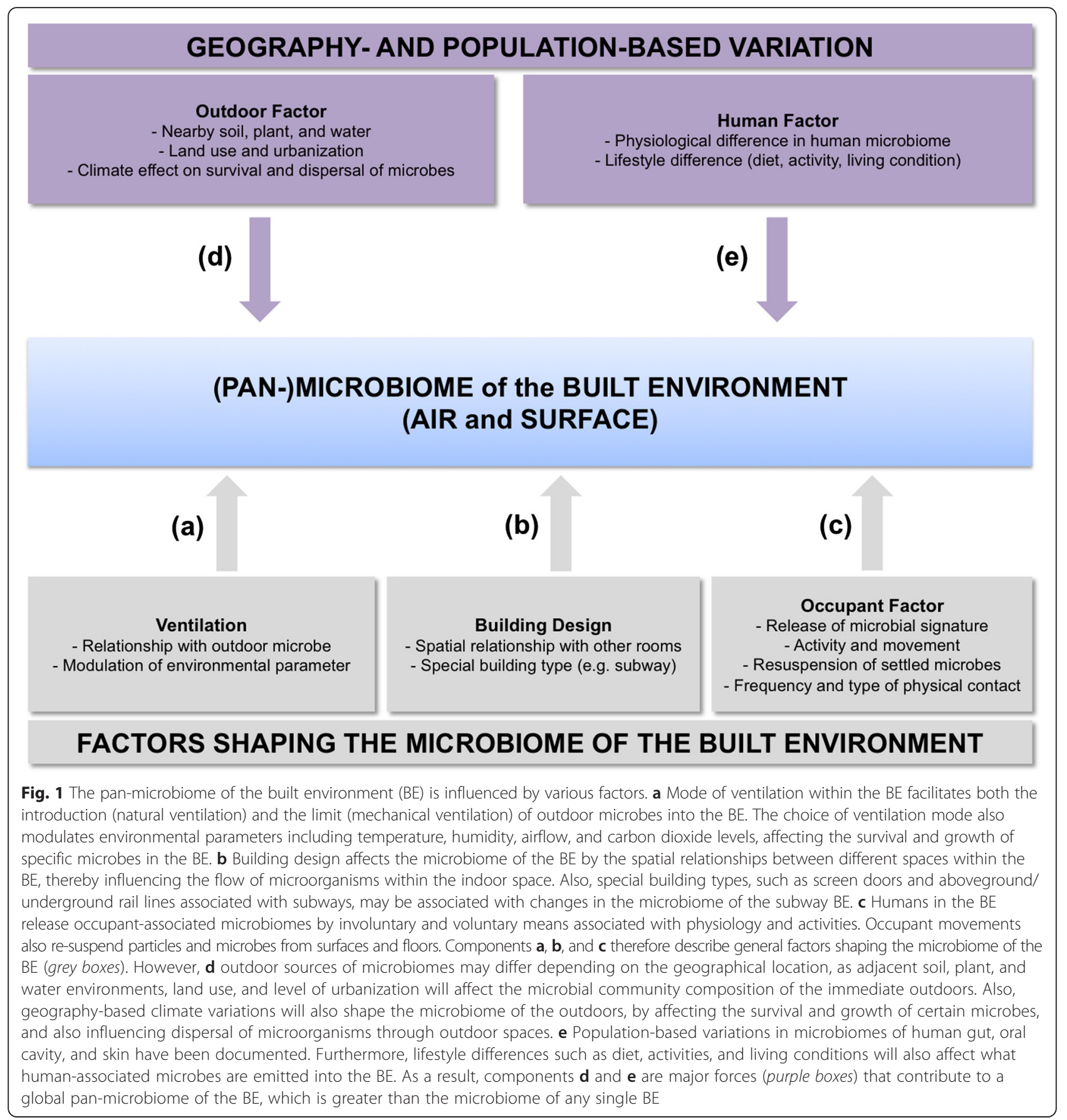

microbiome works using non-weighted community analyses or by taxonomic comparison between studies [26, 77]. For example, the taxonomic comparison of $\mathrm{HK}$ and New York City subway networks reveal that Arthrobacter, Psychrobacter, and Enhydrobacter may be considered distributed bacterial genera [26]. These distributed and endemic taxa can act as drivers of variations in microbiomes across different indoor environments, as they possibly originate from the microbial communities of nearby outdoor and human sources that are influenced by the many geography-associated factors discussed above (terrain, environmental factors, as well as occupant physiology and lifestyles). Following the dispersal from these source environments, various indoor conditions and building parameters that are unique to the $\mathrm{BE}$ will select for microbial members that can survive in a particular indoor environment [10, 53]. Indoor environmental conditions and specific indoor surfaces (such as metallic surfaces) may be associated with variations in the relative abundance of specific microbes [14, 26, 40, 126], while longitudinal studies 


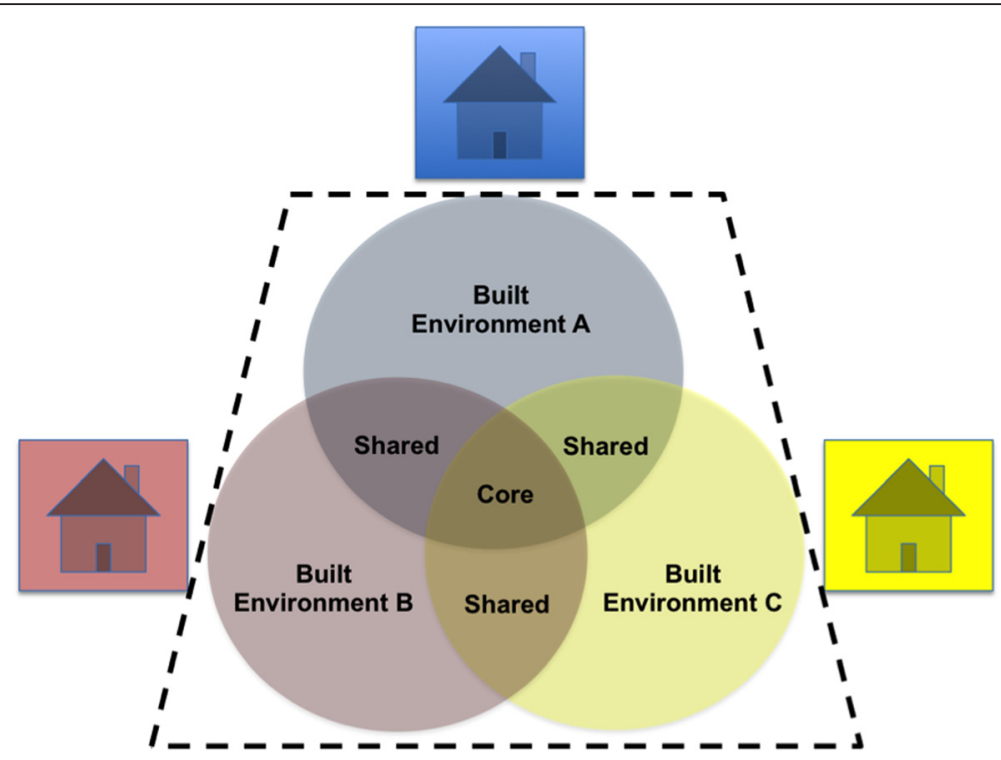

Fig. 2 Different BEs constitute the pan-microbiome of the BE. Comparison of the microbiomes of multiple BEs will reveal taxa (of any taxonomic rank) that are detected in all the BEs, representing the core microbiome (overlapping region in the center). In addition, taxa that are shared between a subset of the BEs will be detected (overlapping area between any two BEs in the figure). Taxa that are specific or unique to a particular BE will also be detected (non-overlapping area). Taxa that are location-unique will contribute to expanding the pan-microbiome of the BE (trapezoid area within black dotted line) and may provide additional information concerning the relationships between building designs, the outdoor and occupant sources, and the microbiome of the specific BE

shed light into identifying microbial members that are transient colonizers of the $\mathrm{BE}$, versus those that may be capable of surviving and persisting within the BE [73, 75]. Taken together, the different outdoor, occupant, and indoor characteristics will ultimately shape the microbiome of a particular $\mathrm{BE}$, and an assessment of microbiomes of a group of BEs will contribute to the pan-microbiome of the global BE.

Understanding the pan-microbiome of the BE has clinical significance. Microbial agents detected in BEs are associated with conditions such as asthma, which affects approximately 300 million individuals around the world [127]. In addition, Hanski and colleagues [128] describe the complex interactive nature between environmental biodiversity, occupant microbiomes, and immune response. Children with atopic epithelial conditions are directly associated with reduced environmental biodiversity in their nearby outdoor environments and lowered microbial diversity of skin microbial colonizers capable of eliciting anti-inflammatory responses. Therefore, it is essential to characterize the distribution of microorganisms across global BEs, as variations in the BE microbiome across the globe, and occupant exposure to allergens and other microbes in BEs, may in part explain geographical variations in the prevalence of allergenic and autoimmune diseases [17, 129]. Also, it has been appreciated that microbes in the BE do not exist and survive in solitude. Rather, microbes co-exist and potentially interact through polymicrobial communities that can alter their physiology, ecology, and virulence [130, 131]. If the microbiomes between BEs are different across geography, it is probable that the nature of potential interactions between microbes within the communities also differ between BEs. Therefore, greater understanding of variations in the microbiome of the $\mathrm{BE}$ in different locations may also shed insight into potential geographical differences in microbial interactions. Clearly, additional work is vital to characterize microbial populations and their interactions in BEs across the globe, evaluate how they are shaped by different building strategies and occupant characteristics, ascertain whether these properties are representative outside of the study area, and determine how these observations correlate with occupant health and productivity.

\section{Future considerations}

With the ever-increasing number of people around the world adopting an indoor lifestyle, the need for a global understanding of the relationships between various building, environmental, and occupant properties and microbial communities in BEs has never been greater. Clearly, a focus in understanding the microbial community of the BE outside the Western world is necessary, as the majority of global citizens live outside the Americas and Europe. While fundamental factors, such as modes of ventilation, building design, and occupant properties and activities discussed previously, may shape microbiomes of BEs around the world in similar manners, 
geographical differences in microbiomes of outdoor and occupant sources may drive community differences between global BEs and ultimately expand the BE panmicrobiome. Predictions about the nature of this community variation, such as how BEs in developing world may differ from that of the developed world, potentially require additional investigations dedicated to the outdoor and occupant microbiome on a global scale. In order for the different studies to be comparable, standardized metadata collection, especially that of environmental conditions, building designs, and occupant characteristics, are of paramount importance. Such efforts can be facilitated by adopting currently available guidelines, as demonstrated in recent studies [132, 133], or by participating in global initiatives that promote the dissemination of laboratory and computational expertise, tools, and integration of scientific data [134, 135]. For now, comparisons between $\mathrm{BE}$ microbiome reports are limited to studies where different sampling, laboratory, bioinformatics, and statistical methodologies are adopted, underscoring the difficulties in generalizing universal relationships between environmental, building, occupant characteristics, and the $\mathrm{BE}$ microbiome $[26,136]$. Thus, future investigations of the microbiome of the $\mathrm{BE}$ around the world should make laboratory workflows and metadata collection consistent, as standardization will undoubtedly empower our ability to determine the shaping forces of microbial communities of the $\mathrm{BE}$ that are globally representative. Notably, Adams et al. advocate the collection of matched outdoor samples to microbiome works of the $\mathrm{BE}$, further emphasizing the importance of understanding the local outdoor environment in shaping the microbiome of indoor spaces [136]. In addition, the use of accurate and consistent terminologies, which is currently a subject of relevance in microbiome research [137], will also benefit the comparison of results across studies.

Also, while HTS technology has been applied to many microbiome investigations of the indoor environment, a great majority of these studies examine the microbial repertoire of the community, without assessing for viability of the detected organisms. It has been reported that as high as $90 \%$ of the total DNA detected in a BE via HTS may originate from non-viable cells [138]. Microorganisms collected in air and on indoor surfaces have been demonstrated to be viable $[75,131,139]$, however HTS transcriptome analysis of the BE will provide a more in-depth and comprehensive evaluation of the metabolically active microbes in indoor spaces. HTS methods can be performed in conjunction with standard photo-reactive dye-based assays (e.g., propidium monoazide), to assess viable subcomponents of the detected microbiomes of the BE $[138,140]$. Through this understanding, we will gain insight into the various building, environmental, and human properties that may act as selective forces. These selective forces, along with dispersal limitation, may ultimately play an important role in shaping location-specific microbial populations across different BEs, hence contributing to the BE panmicrobiome. Understanding these selective forces may also provide support that the indoor microbiome is not simply a residue of the microbiomes of the outdoor and human sources but one that is subjected to unique sets of selective conditions, shaping its unique indoor microbiome.

Microbiome research of the $\mathrm{BE}$ should also recognize that novel buildings, with new building design, will be constructed in the coming years in response to social and environmental issues. For example, the increased need for energy sustainability, a crucial topic of the twenty-first century, calls for indoor spaces with innovative architectural strategies to minimize energy consumption. Green and zero-carbon buildings (ZCBs) are among emerging types of BEs in the developed and developing world, employing novel building characteristics including ventilation, temperature, humidity, landscaping, and occupant density to minimize energy use [141]. Currently, there is no microbiome information regarding such BEs. However, given what is reviewed here, the building characteristics ZCBs try to modulate may also affect the microbiome of the ZCB environment. Therefore, additional works investigating $\mathrm{ZCBs}$ and other emerging BEs around the world are warranted. This knowledge will inform us on how new building designs help structure the BE microbial assemblage and whether geographical variations will be present in these emerging BEs across geography.

\section{Conclusions}

For the past decade, the scientific community has been blessed with the wealth of knowledge about the microbial community structure of the $\mathrm{BE}$, how various building and occupant characteristics structure the microbiology of indoor spaces, and how the outdoors and human act as sources for introducing microorganisms into the indoor environment. However, our current extensive knowledge about microbiome of the $\mathrm{BE}$ in the Western world is met with a relative paucity of microbiome data on indoor settings elsewhere. We are beginning to appreciate that the microbiomes of the outdoors and humans are shaped by geography and associated environmental and occupant factors. At the same time, recent studies reveal the geographical differences in microbiomes of BEs around the globe, contributing to a collective BE pan-microbiome. While the significance of the BE pan-microbiome has not been elucidated, the presence of a global $\mathrm{BE}$ panmicrobiome questions the universality of our current knowledge about indoor microbiology. Additional efforts 
are necessary in identifying general and location-specific relationships between building properties, occupant characteristics, and microbiomes of the $\mathrm{BE}$ across the globe. By investing our efforts into understanding the microbiology of indoor environments in locations where the majority of the world's population resides, we can present universally relevant perspectives on methods to optimize indoor environments. By striving for a global awareness in indoor microbiology, the scientific community will play an invaluable part in improving the health, well-being, and productivity of occupants around the globe.

\section{Additional file}

Additional file 1: List of references used for Table 1. (DOCX $111 \mathrm{~kb}$ )

\section{Abbreviations}

BE: built environment; DNA: deoxyribonucleic acid; GM: gut microbiome/gut microbiota; HK: Hong Kong; HTS: high-throughput sequencing; OM: oral microbiome/microbiota; OTU: operational taxonomic unit; SM: skin microbiome/microbiota; US: United States; ZCB: zero-carbon building.

\section{Competing interests}

The authors declare that they have no competing interests.

\section{Authors' contributions}

MHYL developed and wrote the manuscript. PKHL guided and assisted in writing the manuscript. All authors read and approved the final manuscript.

\section{Acknowledgements}

We thank David Wilkins and Gary Andersen for their constructive comments and valuable contributions to this manuscript. This research was supported by the Research Grants Council of Hong Kong through Projects 124412 and 11211815

Received: 1 December 2015 Accepted: 11 April 2016

Published online: 24 May 2016

\section{References}

1. Amann Rl, Ludwig W, Schleifer KH. Phylogenetic identification and in situ detection of individual microbial cells without cultivation. Microbiol Rev. 1995;59:143-69.

2. Peiffer JA, Spor A, Koren O, Jin Z, Tringe SG, Dangl JL, et al. Diversity and heritability of the maize rhizosphere microbiome under field conditions. Proc Natl Acad Sci. 2013;110:6548-53.

3. Wilkins D, van Sebille E, Rintoul SR, Lauro FM, Cavicchioli R. Advection shapes Southern Ocean microbial assemblages independent of distance and environment effects. Nat Commun. 2013:4:2457.

4. The Human Microbiome Project Consortium. Structure, function and diversity of the healthy human microbiome. Nature. 2012;486:207-14

5. Caporaso JG, Lauber CL, Walters WA, Berg-Lyons D, Huntley J, Fierer N, et al. Ultra-high-throughput microbial community analysis on the Illumina HiSeq and MiSeq platforms. ISME J. 2012;6:1621-4.

6. Klepeis NE, Nelson WC, Ott WR, Robinson JP, Tsang AM, Switzer P, et al. The National Human Activity Pattern Survey (NHAPS): a resource for assessing exposure to environmental pollutants. J Expo Anal Environ Epidemiol. 2001:11:231-52

7. United Nations, Department of Economic and Social Affairs, Population Division. World Urbanization Prospects: The 2014 Revision, (ST/ESA/SER.A/ 366). http://esa.un.org/unpd/wup/highlights/wup2014-highlights.pdf. Accessed 15 Oct 2015

8. World Health Organization. Bulletin of the World Health Organization: Urbanization and Health. http://www.who.int/bulletin/volumes/88/4/10010410/en/. Accessed 15 Oct 2015.
9. Wilkins D, Leung MHY, Lee PKH. Indoor air bacterial communities in Hong Kong households assemble independently of occupant skin microbiomes. Environ Microbiol. 2015;doi:10.1111/1462-2920.12889.

10. Adams RI, Miletto M, Taylor JW, Bruns TD. Dispersal in microbes: fungi in indoor air are dominated by outdoor air and show dispersal limitation at short distances. ISME J. 2013;7:1262-73.

11. Meadow JF, Altrichter AE, Kembel SW, Kline J, Mhuireach G, Moriyama M, et al. Indoor airborne bacterial communities are influenced by ventilation, occupancy, and outdoor air source. Indoor Air. 2014;24:41-8.

12. Dunn RR, Fierer N, Henley JB, Leff JW, Menninger HL. Home life: factors structuring the bacterial diversity found within and between homes. PLoS ONE. 2013;8:e64133.

13. Flores GE, Bates ST, Knights D, Lauber CL, Stombaugh J, Knight R, et al. Microbial biogeography of public restroom surfaces. PLOS ONE. 2011;6:e28132.

14. Flores GE, Bates ST, Caporaso JG, Lauber CL, Leff JW, Knight R, et al. Diversity, distribution and sources of bacteria in residential kitchens. Environ Microbiol. 2013;15:588

15. Angenent LT, Kelley ST, Amand AS, Pace NR, Hernandez MT. Molecular identification of potential pathogens in water and air of a hospital therapy pool. Proc Natl Acad Sci. 2005;102:4860-5.

16. Kettleson E, Kumar S, Reponen T, Vesper S, Méheust D, Grinshpun SA, et al. Stenotrophomonas, Mycobacterium, and Streptomyces in home dust and air: associations with moldiness and other home/family characteristics. Indoor Air. 2013;23:387-96

17. Yamamoto N, Hospodsky D, Dannemiller KC, Nazaroff WW, Peccia J. Indoor emissions as a primary source of airborne allergenic fungal particles in classrooms. Environ Sci Technol. 2015:49:5098-106.

18. Lynch SV, Wood RA, Boushey H, Bacharier LB, Bloomberg GR, Kattan M, et al. Effects of early-life exposure to allergens and bacteria on recurrent wheeze and atopy in urban children. J Allergy Clin Immunol. 2014;134:593-601.e12.

19. Fujimura KE, Demoor T, Rauch M, Faruqi AA, Jang S, Johnson CC, et al. House dust exposure mediates gut microbiome Lactobacillus enrichment and airway immune defense against allergens and virus infection. Proc Natl Acad Sci. 2014;111:805-10.

20. Ege MJ, Mayer M, Normand AC, Genuneit J, Cookson WO, Braun-Fahrländer $\mathrm{C}$, et al. Exposure to environmental microorganisms and childhood asthma. N Engl J Med. 2011;364:701-9.

21. Dannemiller KC, Mendell MJ, Macher JM, Kumagai K, Bradman A, Holland N, et al. Next-generation DNA sequencing reveals that low fungal diversity in house dust is associated with childhood asthma development. Indoor Air. 2014;24:236-47.

22. Kembel SW, Jones E, Kline J, Northcutt D, Stenson J, Womack AM, et al. Architectural design influences the diversity and structure of the built environment microbiome. ISME J. 2012;6:1469-79.

23. Oberauner L, Zachow C, Lackner S, Högenauer C, Smolle KH, Berg G. The ignored diversity: complex bacterial communities in intensive care units revealed by 165 pyrosequencing. Sci Rep. 2013:3:1413.

24. Poza M, Gayoso C, Gómez MJ, Rumbo-Feal S, Tomás M, Aranda J, et al. Exploring bacterial diversity in hospital environments by GS-FLX titanium pyrosequencing. PLoS ONE. 2012;7:e44105.

25. Brooks B, Firek BA, Miller CS, Sharon I, Thomas BC, Baker R, et al. Microbes in the neonatal intensive care unit resemble those found in the gut of premature infants. Microbiome. 2014;2:1.

26. Leung MHY, Wilkins D, Li EKT, Kong FKF, Lee PKH. Indoor-air microbiome in an urban subway network: diversity and dynamics. Appl Environ Microbiol. 2014;80:6760

27. Robertson CE, Baumgartner LK, Harris JK, Peterson KL, Stevens MJ, Frank DN, et al. Culture-independent analysis of aerosol microbiology in a metropolitan subway system. Appl Environ Microbiol. 2013;79:3485-93.

28. Afshinnekoo E, Meydan C, Chowdhury S, Jaroudi D, Boyer C, Bernstein N, et al. Geospatial resolution of human and bacterial diversity with city-scale metagenomics. Cell Syst. 2015;1:72-87.

29. Handorean A, Robertson CE, Harris JK, Frank D, Hull N, Kotter C, et al. Microbial aerosol liberation from soiled textiles isolated during routine residuals handling in a modern health care setting. Microbiome. 2015;3:72

30. Shin H, Pei Z, Martinez KA, Rivera-Vinas Jl, Mendez K, Cavallin H, et al. The first microbial environment of infants born by $C$-section: the operating room microbes. Microbiome. 2015:3:59.

31. Hoisington AJ, Brenner LA, Kinney KA, Postolache TT, Lowry CA. The microbiome of the built environment and mental health. Microbiome. 2015;3:60. 
32. Fisk WJ. Health and productivity gains from better indoor environments and their relationship with building energy efficiency. Annu Rev Energy Environ. 2000;25:537-66.

33. Kettleson EM, Adhikari A, Vesper S, Coombs K, Indugula R, Reponen T. Key determinants of the fungal and bacterial microbiomes in homes. Environ Res. 2015;138:130.

34. Bloom E, Grimsley LF, Pehrson C, Lewis J, Larsson L. Molds and mycotoxins in dust from water-damaged homes in New Orleans after hurricane Katrina. Indoor Air. 2009;19:153-8.

35. Emerson JB, Keady PB, Brewer TE, Clements N, Morgan EE, Awerbuch J, et al. Impacts of flood damage on airborne bacteria and fungi in homes after the 2013 Colorado Front Range flood. Environ Sci Technol. 2015;49:2675-84.

36. Lax S, Smith DP, Hampton-Marcell J, Owens SM, Handley KM, Scott NM, et al. Longitudinal analysis of microbial interaction between humans and the indoor environment. Science. 2014;345:1048-52.

37. Dannemiller KC, Gent JF, Leaderer BP, Peccia J. Influence of housing characteristics on bacterial and fungal communities in homes of asthmatic children. Indoor Air. 2015;doi:10.1111/ina.12205.

38. Nonnenmann MW, Coronado G, Thompson B, Griffith WC, Hanson JD, Vesper S, et al. Utilizing pyrosequencing and quantitative PCR to characterize fungal populations among house dust samples. J Environ Monit. 2012;14:2038-43.

39. Jeon YS, Chun J, Kim BS. Identification of household bacterial community and analysis of species shared with human microbiome. Curr Microbiol. 2013;67:557-63.

40. Adams RI, Miletto M, Taylor JW, Bruns TD. The diversity and distribution of fungi on residential surfaces. PLoS ONE. 2013;8:e78866.

41. Miletto M, Lindow SE. Relative and contextual contribution of different sources to the composition and abundance of indoor air bacteria in residences. Microbiome. 2015;3:61.

42. Meadow JF, Altrichter AE, Kembel SW, Moriyama M, O'Connor TK, Womack AM, et al. Bacterial communities on classroom surfaces vary with human contact. Microbiome. 2014;2:7.

43. Kembel SW, Meadow JF, O'Connor TK, Mhuireach G, Northcutt D, Kline J, et al. Architectural design drives the biogeography of indoor bacterial communities. PLOS ONE. 2014;9:e87093.

44. Petersen TN, Rasmussen S, Hasman H, Carøe C, Bælum J, Charlotte Schultz A, et al. Meta-genomic analysis of toilet waste from long distance flights; a step towards global surveillance of infectious diseases and antimicrobial resistance. Sci Rep. 2015;5:11444.

45. Tringe SG, Zhang T, Liu X, Yu Y, Lee WH, Yap J, et al. The airborne metagenome in an indoor urban environment. PLOS ONE. 2008;3:e1862.

46. Mukherjee N, Dowd SE, Wise A, Kedia S, Vohra V, Banerjee P. Diversity of bacterial communities of fitness center surfaces in a U.S. metropolitan area. Int J Environ Res Public Health. 2014;11:12544-61.

47. Wood M, Gibbons SM, Lax S, Eshoo-Anton TW, Owens SM, Kennedy S, et al. Athletic equipment microbiota are shaped by interactions with human skin. Microbiome. 2015;3:25

48. Adams Rl, Bhangar S, Pasut W, Arens EA, Taylor JW, Lindow SE, et al. Chamber bioaerosol study: outdoor air and human occupants as sources of indoor airborne microbes. PLoS ONE. 2015;10:e0128022.

49. Hewitt KM, Gerba CP, Maxwell SL, Kelley ST. Bacterial abundance and diversity in three metropolitan areas. PLOS ONE. 2012;7:e37849.

50. Shin SK, Kim J, Ha SM, Oh HS, Chun J, Sohn J, et al. Metagenomic insights into the bioaerosols in the indoor and outdoor environments of childcare facilities. PLOS ONE. 2015;10:e0126960.

51. Barberán A, Dunn RR, Reich BJ, Pacifici K, Laber EB, Menninger HL, et al. The ecology of microscopic life in household dust. Proc R Soc B. 2015;282:20151139.

52. Adams RI, Miletto M, Lindow SE, Taylor JW, Bruns TD. Airborne bacterial communities in residences: similarities and differences with Fungi. PLOS ONE. 2014;9:e91283.

53. Kelley ST, Gilbert JA. Studying the microbiology of the indoor environment. Genome Biol. 2013;14:202.

54. Hospodsky D, Qian J, Nazaroff WW, Yamamoto N, Bibby K, Rismani-Yazdi H, et al. Human occupancy as a source of indoor airborne bacteria. PLoS ONE. 2012;7:e34867.

55. Bowers RM, McLetchie S, Knight R, Fierer N. Spatial variability in airborne bacterial communities across land-use types and their relationship to the bacterial communities of potential source environments. ISME J. 2011;5:601-12
56. Amend AS, Seifert KA, Samson R, Bruns TD. Indoor fungal composition is geographically patterned and more diverse in temperate zones than in the tropics. Proc Natl Acad Sci. 2010;107:13748-53.

57. Prussin AJ, Marr LC. Sources of airborne microorganisms in the built environment. Microbiome. 2015;3:78.

58. Schnorr SL, Candela M, Rampelli S, Centanni M, Consolandi C, Basaglia G, et al. Gut microbiome of the Hadza hunter-gatherers. Nat Commun. 2014;5:3654.

59. Clemente J, Pehrsson E, Blaser M, Sandhu K, Gao Z, Wang B, et al. The microbiome of uncontacted Amerindians. Sci Adv. 2015;1:e1500183.

60. Bonetta S, Bonetta S, Mosso S, Sampò S, Carraro E. Assessment of microbiological indoor air quality in an Italian office building equipped with an HVAC system. Environ Monit Assess. 2010;161:473-83.

61. Pasanen AL, Kalliokoski P, Pasanen P, Salmi T, Tossavainen A. Fungi carried from farmers' work into farm homes. Am Ind Hyg Assoc J. 1989;50:631-3.

62. Lee L, Tin S, Kelley ST. Culture-independent analysis of bacterial diversity in a child-care facility. BMC Microbiol. 2007;7:27.

63. Shelton BG, Kirkland KH, Flanders WD, Morris GK. Profiles of airborne fungi in buildings and outdoor environments in the United States. Appl Environ Microbiol. 2002;68:1743-53.

64. Andersson AM, Weiss N, Rainey F, Salkinoja-Salonen MS. Dust-borne bacteria in animal sheds, schools and children's day care centres. J Appl Microbiol. 1999:86:622-34.

65. Rautiala S, Torvinen E, Torkko P, Suomalainen S, Nevalainen A, Kalliokoski P, et al. Potentially pathogenic, slow-growing mycobacteria released into workplace air during the remediation of buildings. J Occup Environ Hyg. 2004;1:1-6.

66. Zalar P, Novak M, de Hoog GS, Gunde-Cimerman N. Dishwashers-a man-made ecological niche accommodating human opportunistic fungal pathogens. Fungal Biol. 2011;115:997-1007.

67. Pitkäranta M, Meklin T, Hyvärinen A, Paulin L, Auvinen P, Nevalainen A, et al. Analysis of fungal flora in indoor dust by ribosomal DNA sequence analysis, quantitative PCR, and culture. Appl Environ Microbiol. 2008;74:233-44.

68. Pitkäranta M, Meklin T, Hyvärinen A, Nevalainen A, Paulin L, Auvinen P, et al. Molecular profiling of fungal communities in moisture damaged buildings before and after remediation-a comparison of culture-dependent and culture-independent methods. BMC Microbiol. 2011;11:235.

69. Täubel M, Rintala H, Pitkäranta M, Paulin L, Laitinen S, Pekkanen J, et al. The occupant as a source of house dust bacteria. J Allergy Clin Immunol. 2009;124:834-840.e47.

70. Rintala H, Pitkäranta M, Toivola M, Paulin L, Nevalainen A. Diversity and seasonal dynamics of bacterial community in indoor environment. BMC Microbiol. 2008;8:56

71. Kelley ST, Theisen U, Angenent LT, Amand AS, Pace NR. Molecular analysis of shower curtain biofilm microbes. Appl Environ Microbiol. 2004;70:4187-92.

72. Ke MT, Cheng TC, Wang WP. Numerical simulation for optimizing the design of subway environmental control system. Build Environ. 2002;37:1139-52.

73. Ross AA, Neufeld JD. Microbial biogeography of a university campus. Microbiome. 2015;3:66

74. Hospodsky D, Yamamoto N, Nazaroff WW, Miller D, Gorthala S, Peccia J. Characterizing airborne fungal and bacterial concentrations and emission rates in six occupied children's classrooms. Indoor Air. 2015;25:641-52.

75. Gibbons SM, Schwartz T, Fouquier J, Mitchell M, Sangwan N, Gilbert JA, et al. Ecological succession and viability of human-associated microbiota on restroom surfaces. Appl Environ Microbiol. 2015;81:765-73.

76. Meadow JF, Altrichter AE, Bateman AC, Stenson J, Brown G, Green JL, et al. Humans differ in their personal microbial cloud. PeerJ. 2015;3:e1258.

77. Lax S, Hampton-Marcell JT, Gibbons SM, Colares GB, Smith D, Eisen JA, et al. Forensic analysis of the microbiome of phones and shoes. Microbiome. 2015;3:21.

78. Meadow JF, Altrichter AE, Green JL. Mobile phones carry the personal microbiome of their owners. PeerJ. 2014;2:e447.

79. Franzosa EA, Huang K, Meadow JF, Gevers D, Lemon KP, Bohannan BJM, et al. Identifying personal microbiomes using metagenomic codes. Proc Natl Acad Sci. 2015;112:E2930-8.

80. Fierer N, Lauber CL, Zhou N, McDonald D, Costello EK, Knight R. Forensic identification using skin bacterial communities. Proc Natl Acad Sci. 2010;107:6477-81.

81. Qian J, Hospodsky D, Yamamoto N, Nazaroff WW, Peccia J. Size-resolved emission rates of airborne bacteria and fungi in an occupied classroom. Indoor Air. 2012;22:339-51. 
82. Heydenreich B, Bellinghausen I, König B, Becker WM, Grabbe S, Petersen A, et al. Gram-positive bacteria on grass pollen exhibit adjuvant activity inducing inflammatory T cell responses. Clin Exp Allergy. 2012;42:76-84.

83. Fujimura KE, Johnson CC, Ownby DR, Cox MJ, Brodie EL, Havstad SL, et al. Man's best friend? The effect of pet ownership on house dust microbial communities. J Allergy Clin Immunol. 2010;126:410-412.e3.

84. Baldrian P, Kolařík M, Štursová M, Kopecký J, Valášková V, Větrovský T, et al. Active and total microbial communities in forest soil are largely different and highly stratified during decomposition. ISME J. 2012;6:248-58.

85. Harding T, Jungblut AD, Lovejoy C, Vincent WF. Microbes in high arctic snow and implications for the cold biosphere. Appl Environ Microbiol. 2011;77:3234-43.

86. DeLeon-Rodriguez N, Lathem TL, Rodriguez-R LM, Barazesh JM, Anderson $\mathrm{BE}$, Beyersdorf AJ, et al. Microbiome of the upper troposphere: species composition and prevalence, effects of tropical storms, and atmospheric implications. Proc Natl Acad Sci. 2013;110:2575-80.

87. Seifried JS, Wichels A, Gerdts G. Spatial distribution of marine airborne bacterial communities. Microbiologyopen. 2015;4:475-90.

88. Bottos EM, Woo AC, Zawar-Reza P, Pointing SB, Cary SC. Airborne bacterial populations above desert soils of the McMurdo Dry Valleys, Antarctica. Microb Ecol. 2014;67:120-8

89. Jones AM, Harrison RM. The effects of meteorological factors on atmospheric bioaerosol concentrations-a review. Sci Total Environ. 2004:326:151-80.

90. Brodie EL, DeSantis TZ, Parker JPM, Zubietta IX, Piceno YM, Andersen GL. Urban aerosols harbor diverse and dynamic bacterial populations. Proc Natl Acad Sci. 2007;104:299-304.

91. Bowers RM, McCubbin IB, Hallar AG, Fierer N. Seasonal variability in airborne bacterial communities at a high-elevation site. Atmos Environ. 2012;50:41-9.

92. Woo AC, Brar MS, Chan Y, Lau MCY, Leung FCC, Scott JA, et al. Temporal variation in airborne microbial populations and microbially-derived allergens in a tropical urban landscape. Atmos Environ. 2013;74:291-300.

93. Barberán A, Ladau J, Leff JW, Pollard KS, Menninger HL, Dunn RR, et al. Continental-scale distributions of dust-associated bacteria and fungi. Proc Natl Acad Sci. 2015;112:5756.

94. Grantham NS, Reich BJ, Pacifici K, Laber EB, Menninger HL, Henley JB, et al. Fungi identify the geographic origin of dust samples. PLoS ONE. 2015;10:e0122605.

95. Jablonski NG. "Ethnic skin" and why the study of human cutaneous diversity is important. Br J Dermatol. 2013;169 Suppl S3:V.

96. Leung MHY, Wilkins $\mathrm{D}$, Lee PKH. Insights into the pan-microbiome: skin microbial communities of Chinese individuals differ from other racial groups. Sci Rep. 2015;5:11845.

97. Blaser MJ, Dominguez-Bello MG, Contreras M, Magris M, Hidalgo G, Estrada I, et al. Distinct cutaneous bacterial assemblages in a sampling of South American Amerindians and US residents. ISME J. 2013;7:85-95.

98. Fortenberry JD. The uses of race and ethnicity in human microbiome research. Trends Microbiol. 2013;21:165-6.

99. De Filippo C, Cavalieri D, Paola MD, Ramazzotti M, Poullet JB, Massart S, et al. Impact of diet in shaping gut microbiota revealed by a comparative study in children from Europe and rural Africa. Proc Natl Acad Sci. 2010:107:14691-6.

100. Yatsunenko T, Rey FE, Manary MJ, Trehan I, Dominguez-Bello MG, Contreras $\mathrm{M}$, et al. Human gut microbiome viewed across age and geography. Nature. 2012;486:222-7.

101. Martínez I, Stegen JC, Maldonado-Gómez MX, Eren AM, Siba PM, Greenhill AR, et al. The gut microbiota of rural Papua New Guineans: composition, diversity patterns, and ecological processes. Cell Rep. 2015;11:527-38.

102. Obregon-Tito AJ, Tito RY, Metcalf J, Sankaranarayanan K, Clemente JC, Ursell LK, et al. Subsistence strategies in traditional societies distinguish gut microbiomes. Nat Commun. 2015;6:6505.

103. Nakayama J, Watanabe K, Jiang J, Matsuda K, Chao SH, Haryono P, et al. Diversity in gut bacterial community of school-age children in Asia. Sci Rep. 2015;5:8397.

104. Zhang J, Guo Z, Xue Z, Sun Z, Zhang M, Wang L, et al. A phylo-functional core of gut microbiota in healthy young Chinese cohorts across lifestyles, geography and ethnicities. ISME J. 2015;9:1979-90.

105. Kwok L, Zhang J, Guo Z, Gesudu Q, Zheng Y, Qiao J, et al. Characterization of fecal microbiota across seven Chinese ethnic groups by quantitative polymerase chain reaction. PLOS ONE. 2014;9:e93631.

106. Hester CM, Jala VR, Langille MG, Umar S, Greiner KA, Haribabu B. Fecal microbes, short chain fatty acids, and colorectal cancer across racial/ethnic groups. World J Gastroenterol. 2015;21:2759-69.
107. Tito RY, Knights D, Metcalf J, Obregon-Tito AJ, Cleeland L, Najar F, et al. Insights from characterizing extinct human gut microbiomes. PLoS ONE. 2012;7:e51146.

108. David LA, Materna AC, Friedman J, Campos-Baptista MI, Blackburn MC, Perrotta A, et al. Host lifestyle affects human microbiota on daily timescales. Genome Biol. 2014;15:R89.

109. Cruz GD, Chen Y, Salazar CR, Le Geros RZ. The association of immigration and acculturation attributes with oral health among immigrants in New York City. Am J Public Health. 2009;99 Suppl 2:S474-80.

110. Nasidze I, Li J, Quinque D, Tang K, Stoneking M. Global diversity in the human salivary microbiome. Genome Res. 2009;19:636-43.

111. Mason MR, Nagaraja HN, Camerlengo T, Joshi V, Kumar PS. Deep sequencing identifies ethnicity-specific bacterial signatures in the oral microbiome. PLoS ONE. 2013;8:e77287.

112. Ghannoum MA, Jurevic RJ, Mukherjee PK, Cui F, Sikaroodi M, Naqvi A, et al. Characterization of the oral fungal microbiome (mycobiome) in healthy individuals. PLoS Pathog. 2010;6:e1000713.

113. Ying S, Zeng DN, Chi L, Tan Y, Galzote C, Cardona C, et al. The influence of age and gender on skin-associated microbial communities in urban and rural human populations. PLoS ONE. 2015;10:e0141842.

114. Hospodsky D, Pickering AJ, Julian TR, Miller D, Gorthala S, Boehm AB, et al. Hand bacterial communities vary across two different human populations. Microbiology. 2014;160(Pt 6):1144-52.

115. Grice EA, Kong HH, Conlan S, Deming CB, Davis J, Young AC, et al. Topographical and temporal diversity of the human skin microbiome. Science. 2009:324:1190-2.

116. Findley K, Oh J, Yang J, Conlan S, Deming C, Meyer JA, et al. Topographic diversity of fungal and bacterial communities in human skin. Nature. 2013:498:367-70.

117. Wesley NO, Maibach HI. Racial (ethnic) differences in skin properties: the objective data. Am J Clin Dermatol. 2003;4:843-60.

118. Fierer N, Hamady M, Lauber CL, Knight R. The influence of sex, handedness, and washing on the diversity of hand surface bacteria. Proc Natl Acad Sci. 2008; 105:17994

119. Sugita T, Yamazaki T, Yamada S, Takeoka H, Cho O, Tanaka T, et al. Temporal changes in the skin Malassezia microbiota of members of the Japanese Antarctic Research Expedition (JARE): a case study in Antarctica as a pseudo-space environment. Med Mycol. 2015;53:717-24.

120. Meadow JF, Bateman AC, Herkert KM, O'Connor TK, Green JL. Significant changes in the skin microbiome mediated by the sport of roller derby. PeerJ. 2013:1:e53.

121. Ling Z, Liu X, Luo Y, Yuan L, Nelson KE, Wang Y, et al. Pyrosequencing analysis of the human microbiota of healthy Chinese undergraduates. BMC Genomics. 2013;14:390.

122. Gaüzère C, Moletta-Denat M, Blanquart H, Ferreira S, Moularat S, Godon JJ, et al. Stability of airborne microbes in the Louvre Museum over time. Indoor Air. 2014;24:29-40.

123. Zeeuwen PL, Boekhorst J, van den Bogaard EH, de Koning HD, van de Kerkhof PM, Saulnier DM, et al. Microbiome dynamics of human epidermis following skin barrier disruption. Genome Biol. 2012;13:R101.

124. Hanson CA, Fuhrman JA, Horner-Devine MC, Martiny JBH. Beyond biogeographic patterns: processes shaping the microbial landscape. Nat Rev Microbiol. 2012;10:497-506.

125. Gaüzère C, Godon JJ, Blanquart H, Ferreira S, Moularat S, Robine E, et al. "Core species" in three sources of indoor air belonging to the human micro-environment to the exclusion of outdoor air. Sci Total Environ. 2014;485-486:508-17.

126. Frankel M, Bekö G, Timm M, Gustavsen S, Hansen EW, Madsen AM. Seasonal variations of indoor microbial exposures and their relation to temperature, relative humidity, and air exchange rate. Appl Environ Microbiol. 2012;78:8289-97.

127. Masoli M, Fabian D, Holt S, Beasley R. Global Initiative for Asthma (GINA) Program. The global burden of asthma: executive summary of the GINA Dissemination Committee Report. Allergy. 2004;59:469-78.

128. Hanski I, von Hertzen L, Fyhrquist N, Koskinen K, Torppa K, Laatikainen T, et al. Environmental biodiversity, human microbiota, and allergy are interrelated. Proc Natl Acad Sci. 2012;109:8334-9.

129. Salo PM, Arbes SJ, Sever M, Jaramillo R, Cohn RD, London SJ, et al. Exposure to Alternaria alternata in US homes is associated with asthma symptoms. J Allergy Clin Immunol. 2006;118:892-8.

130. Feazel LM, Baumgartner LK, Peterson KL, Frank DN, Harris JK, Pace NR. Opportunistic pathogens enriched in showerhead biofilms. Proc Natl Acad Sci. 2009;106:16393-9. 
131. Marks $L R$, Reddinger RM, Hakansson AP. Biofilm formation enhances fomite survival of Streptococcus pneumoniae and Streptococcus pyogenes. Infect Immun. 2014;82:1141.

132. Glass EM, Dribinsky Y, Yilmaz P, Levin H, Van Pelt R, Wendel D, et al. MIXS-BE: a MIXS extension defining a minimum information standard for sequence data from the built environment. ISME J. 2014;8:1-3.

133. Ramos T, Dedesko S, Siegel JA, Gilbert JA, Stephens B. Spatial and temporal variations in indoor environmental conditions, human occupancy, and operational characteristics in a new hospital building. PLoS ONE. 2015;10:e0118207.

134. Dubilier N, McFall-Ngai M, Zhao L. Microbiology: create a global microbiome effort. Nature. 2015;526:631-4.

135. Alivisatos AP, Blaser MJ, Brodie EL, Chun M, Dangl JL, Donohue TJ, et al. A unified initiative to harness Earth's microbiomes. Science. 2015;350:507-8.

136. Adams Rl, Bateman AC, Bik HM, Meadow JF. Microbiota of the indoor environment: a meta-analysis. Microbiome. 2015;3:49.

137. Marchesi JR, Ravel J. The vocabulary of microbiome research: a proposal. Microbiome. 2015;3:31

138. Vaishampayan P, Probst AJ, La Duc MT, Bargoma E, Benardini JN, Andersen $\mathrm{GL}$, et al. New perspectives on viable microbial communities in low-biomass cleanroom environments. ISME J. 2013;7:312-24.

139. Womack AM, Bohannan BJM, Green JL. Biodiversity and biogeography of the atmosphere. Phil Trans R Soc B. 2010;365:3645-53.

140. Weinmaier T, Probst AJ, Duc MT, Ciobanu D, Cheng JF, Ivanova N, et al. A viability-linked metagenomic analysis of cleanroom environments: eukarya, prokaryotes, and viruses. Microbiome. 2015;3:62.

141. Marszal AJ, Heiselberg P, Bourrelle JS, Musall E, Voss K, Sartori I, et al. Zero energy building - a review of definitions and calculation methodologies. Energy Build. 2011;43:971-9.

\section{Submit your next manuscript to BioMed Central and we will help you at every step:}

- We accept pre-submission inquiries

- Our selector tool helps you to find the most relevant journal

- We provide round the clock customer support

- Convenient online submission

- Thorough peer review

- Inclusion in PubMed and all major indexing services

- Maximum visibility for your research

Submit your manuscript at www.biomedcentral.com/submit

) Biomed Central 